\title{
O ESTADO MODERNO E O REGIME DEMOCRÁTICO
}

\author{
Lucas Ferreira Furlan, Alessandro Severino Vallér Zenni.
}

Centro Universitário de Maringá - Mestrado em Ciências Jurídicas. Email: lucasfurlan94@hotmail.com

\section{RESUMO}

O presente estudo traçou uma linha de correlação entre a evolução do Estado Moderno e o regime democrático. Inicialmente foram tecidas breves considerações quanto à origem do Estado como organização política e suas características. Posteriormente, com a síntese necessária, ponderou-se a respeito da evolução do regime democrático dando destaque as suas modalidades de manifestação ao longo da história, a saber: democracia direta, semidireta e representativa. Encerrando-se o desenvolvimento do trabalho foram feitas breves considerações quanto a indispensável concessão de confiança por parte dos cidadãos as instituições democráticas e seus representantes, como forma de estabilidade do regime. Por fim, foram tecidas as considerações finais.

Palavras-chave: Democracia, Estado, Regime e Representação.

\section{THE MODERN STATE AND THE DEMOCRATIC REGIME}

\section{ABSTRACT}

The present study draws a line of correlation between the evolution of the Modern State and the democratic regime. Initially brief considerations were made regarding the origin of the State as a political organization, with its current characteristics. Subsequently, with the necessary synthesis, we pondered on the evolution of the democratic regime, highlighting its manifestations throughout history, namely: direct, semi-direct and representative democracy. At the end of the development of the work, brief considerations were made as to the indispensable granting of confidence by the citizens of democratic institutions and their representatives, as a form of stability of the regime. Finally, the final considerations were woven.

Keywords: Democracy, State, Regime and Representation.

\section{INTRODUÇÃO}

Delimitar os atos e fatos que deságuam no nascimento de um Estado é tão complexo quanto narrar à história de cada um destes. Os Estados podem se originar a partir de um processo gradual de evolução, como também surgirem de um processo de revolução ou mesmo por uma união ou divisão de outros Entes Soberanos (PINTO, 2013, p. 115).

Fixada tal premissa, pode-se afirmar que os Estados antigos originaram-se em decorrência deste mencionado processo de evolução natural, partindo majoritariamente de fatores relacionados a questões familiares, imposições pelo critério da força e até mesmo já se pautando em questões patrimoniais, sendo que a doutrina abarca teorias defensoras de todas estas possibilidades (FACHIN; SAMPAR, 2016, p. 25).
Contudo, os Estado primitivos e antigos Impérios se extinguiram, sendo que com seu fim criaram-se os Estados Modernos, os quais em sua maioria guardam tradições e semelhanças culturais com os antigos Entes Soberanos que Ihes originaram, similitudes estas, porém, que majoritariamente não se fazem presentes no campo da geopolítica dos novos Estados (MALUF, 2017, p. 70).

O Estado Moderno como hoje conhecido, possui grande aspiração democrática, confrontando-se, portanto, ao autoritarismo majoritariamente presente nos impérios da Idade Antiga. A ideia de construção de um Ente Soberano pautado em viés democrático tem suas raízes no século XVIII, ante o florescimento do debate quanto aos valores inerentes à personalidade humana. 
Porém, a existência de mecanismos que permitam a adequada participação popular na administração estatal não se configura em uma realidade de fácil alcance, sendo que a criação de sistemas representativos que permitam uma maior participação social no processo decisório do Estado Moderno tem se configurado numa das maiores dificuldades da realidade moderna (DALLARI, 2012, p. 145).

Segundo Hans Kelsen, a democracia estaria efetivada quando fosse possível verificar a efetiva participação dos governados nas escolhas de seus governantes e na elaboração do ordenamento normativo do Estado (KELSEN, apud. FILOMENO, 2016, p. 123), porém, como já mencionado, tal equação não é de fácil solução, visto que definir o que seria a adequada participação da sociedade nestes temas é consideravelmente complexo.

O objetivo do presente trabalho é realizar uma sucinta explanação quanto ao Estado Moderno, bem como, tecer considerações quanto à escolha da democracia como seu regime político, em especial na sua modalidade representativa.

\section{METODOLOGIA}

O artigo foi norteado por pesquisas bibliográficas, leituras e fichamentos. A delimitação do tema foi realizada com base na pertinência do assunto, bem como, na finalidade objetivada pelo presente estudo. Os conhecimentos prévios existentes juntamente comas possibilidades de tempo e pesquisa disponíveis delimitaram a profundidade da abordagem realizada

\section{RESULTADOS}

Os resultados alcançados com a presente pesquisa foram concretos, de forma a contribuir com a análise e estudo do Estado Moderno, bem como, quanto à efetivação dos mecanismos de representação democrática.

\section{O ESTADO MODERNO E A DEMOCRACIA}

Como já ponderado, existe uma variada gama de teorias que buscam demonstrar e debater quais fatores originaram a criação do Estado como hoje o conhecemos, sendo que para finalidade da presente pesquisa não se mostra pertinente adentrarmos neste mérito. Buscaremos discorrer sobre a concepção do Estado Moderno e sua relação com a democracia.

Para doutrina majoritária, o Estado Moderno se originou a partir da assinatura dos tratados de Paz de Vestfália, os quais fortaleceram o modelo de Estado soberano como hoje conhecido e conceituado. Tal realidade fora precedida de uma longa evolução histórica, sendo que ainda neste período os Estados encontravam-se sob égide das monarquias absolutistas, as quais serviram de transição para o modelo hoje conhecido (FACHIN; SAMPAR, 2016, p. 53).

Como ponderado, em que pese o Estado já gozasse das características inerentes a sua condição, ainda era governado com foco absoluto na figura do monarca, sendo que tal realidade fora responsável pelas mais variadas formas de violação da dignidade humana e obstrução da vontade popular.

Em face de tal situação, os movimentos contrários aos absolutismos começaram a surgir. A imposição da Carta Magna em 1215 é tida por muitos como o primeiro de uma série de movimentos com o objetivo de limitar o poder do monarca, os quais culminaram com a Revolução Francesa em 1789, a qual fora responsável por uma nova estruturação teórica do poder (PINTO, 2013, p. 232).

Tendo o Estado alcançado, mesmo que precariamente, as características a ele inerentes, ou seja, território delimitado, povo e governo soberano, o decurso do tempo foi responsável pela efetivação destas, sendo que como bem apontado pela doutrina, a sua definição e preservação se converteram em objetivos do próprio Estado (DALLARI, 2012, p. 78).

Porém, quando do estudo da evolução histórica do Estado uma grande pergunta emerge: Qual seria a sua finalidade ou justificação? Majoritariamente, entende-se que a formação do Estado encontra-se justificada na própria existência humana, sendo que o homem necessita deste para satisfação de suas necessidades fundamentais, as quais não conseguiria suprir sozinho (FILOMENO, 2016, p. 69).

Nesta linha, seguindo os ensinamentos da Teoria Contratualista, pode-se afirmar que o Estado funciona como uma espécie de protetor do individuo, responsável por assegurar a paz e a defesa comum (HOBBES, 2014, p. 142), regulamentando as relações sociais entre seus componentes ao mesmo tempo em que respeita e garante os direitos fundamentais da pessoa humana.

Assim, considerando-se que o Estado obtém sua justificação na garantia da paz e da 
defesa comum de seus componentes, pode-se argumentar que este fator seja igualmente acrescentando entre os elementos caracterizadores do Ente Soberano, podendo a garantia do bem comum ser classificada como a finalidade do Estado Moderno (FACHIN; SAMPAR, 2016, p. 25).

Desta feita, fixada a premissa de que a finalidade do Estado encontra-se em buscar o bem comum dos indivíduos que o compõem, torna-se necessário debater por quais meios poderá se alcançar este fim. Neste diapasão, floresce o debate quanto aos tipos de regime político que podem ser adotados pelo Estado Moderno.

Tal afirmativa pode ser realizada, visto que para grande parte da doutrina, o regime político possui uma estrita ligação com a questão finalística do Estado, podendo ser compreendido como a sistematização dos meios de exercício da soberania estatal, com o fim de se alcançar o bem-estar social almejado (PINTO, 2013, p. 163).

Como já ponderado, o Estado Moderno possui uma indiscutível inclinação pelo regime democrático, sendo que dentre os diversos modos de exercício do poder político, este se constitui no sistema em que poder político estatal é exercido pelo povo ou ao menos, pela maioria do povo (BOBBIO, 1987, p. 135). Essa preferência se mostra de certa forma coerente, sobretudo, ante a finalidade da organização estatal.

Diante de tal realidade houve o surgimento do Estado Democrático de Direito, o qual para muitos se configura em uma espécie de aperfeiçoamento da forma de Estado até então existente. Este modelo ganhou força a após a queda dos governos autoritários surgidos na Europa na primeira metade do século $X X$, havendo com a sua implantação uma proeminência da democracia na tomada de decisões e na defesa dos direitos individuais (FACHIN; SAMPAR, 2016, p. 70).

Desta forma, como o passar dos tempos e o consequente aprimoramento das instituições sociais, criou-se um consenso quanto à necessidade da busca pela efetivação do Estado Democrático, de forma que qualquer sistema ou governo contemporâneo afirme seu caráter democrático, mesmo quando dotado das mais patentes práticas totalitárias (DALLARI, 2012, p. 151). No próximo tópico serão tecidas ponderações quanto ao referido regime político.

\section{A DEMOCRACIA COMO REGIME POLÍTICO.}

$O$ regime democrático possui uma longa construção histórica, sendo que suas raízes se encontram no pensamento grego clássico. Atualmente, a democracia configurou-se como o principal pilar de organização política do Estado Moderno, apesar desta possuir contemporaneamente uma aplicação prática razoavelmente destoante da existente na Grécia Antiga (BIELSCHWSKY, 2013, p. 51).

A expressão democracia se origina dos radicais demo (povo) e kratos (poder). Desta forma, na linha do já exposto, o referido regime político caracteriza-se pela efetiva participação da sociedade nas decisões políticas do Estado, seja por meio de representantes para este fim escolhidos ou mesmo de maneira direta (PINTO, 2013, p. 167).

Em outras palavras, a democracia surgiu como um regime de organização política, no qual a direção geral dos interesses da coletividade é ditada pela maioria do povo que compõem o Estado, seguindo ditames e normas legais que garantam a efetiva participação social na formação da administração pública, com grande preocupação no reconhecimento e na garantia dos direitos fundamentais (MALUF, 2017, p. 315).

Ao longo da história, o sistema democrático fora aplicado de variadas formas, originariamente, ainda na Grécia Antiga, houve a manifestação da democracia direta, por meio da qual aqueles que eram considerados cidadãos deliberavam diretamente quanto às normas de convivência social, ou seja, não havia qualquer intermediação entre governantes e governados (FILOMENO, 2016, p. 128).

Hodiernamente, dada a dificuldade de aplicação prática do regime de democracia direta houve uma majoritária adoção do sistema de democracia representativa, em que pese boa parte dos Estados Modernos ainda aplicarem mecanismos de representação direta do cidadão para a tomada de certas decisões, fazendo surgir a chamada democracia semidireta.

Assim, na democracia semidireta, podese afirmar que as deliberações de interesse do Estado são realizadas pelos representantes do povo, os quais foram para esse fim escolhidos, mas há possibilidade de que algumas decisões sejam por aquele, diretamente tomadas. Para possibilidade de efetivação desta modalidade de democracia destacam-se os institutos do plebiscito, referendo e a iniciativa popular. 
Nessa linha, é sabido que o sistema democrático tem como principal finalidade a garantia de efetiva participação social na tomada das decisões do Estado, contudo, nem sempre tal objetivo possui fácil alcance, visto a existência de diversos obstáculos de ordem prática. Ora, no sistema de democracia representativa, os mandatários do Estado são investidos nessa condição por meio da vontade popular, representada pelo voto da maioria dos cidadãos.

Neste ponto, surge o primeiro desafio do Estado Democrático já que via de regra, somente uma parte da população do Estado é chamada a escolha de seus representantes, isso dada a exigência legal do prévio preenchimento de certos requisitos por parte dos componentes do corpo social, para o exercício de seu direito de escolha.

Contudo, os representantes eleitos terão o dever de governar para toda a população e não somente para os votantes, se considerarmos ainda, que em muitos casos os eleitos são escolhidos por maioria simples ou mesmo que somente uma minoria dos eleitores comparece ao pleito, podemos concluir que em um regime democrático à vontade popular nem sempre é expressa pela maioria da sociedade (MALUF, 2017, p. 314).

Diante dessa realidade narrada, resta claro que a efetivação de uma democracia representativa não se configura em uma realidade de fácil alcance, sendo que o Estado precisa contar com diversos mecanismos e sistemas de participação, aptos a garantir a efetiva prevalência da vontade da maioria, somada a necessária atenção e respeito aos anseios das minorias.

\section{DA CONFIANÇA NO REGIME DEMOCRÁTICO.}

Dentre os mais diversos fatores que podem influenciar a estabilidade do regime democrático no âmbito do Estado Moderno, sem dúvidas deve-se se conferir especial destaque a confiança política existente por parte dos cidadãos na atuação das instituições democráticas e por consequência em seus representantes.

Ante tal realidade, nas últimas décadas, os cientistas políticos têm realizado diversos estudos quanto aos motivos que levam os cidadãos a dispensarem ou não credibilidade as instituições públicas e por consequência a todo regime político, como também, quais fatores levariam a queda de credibilidade das instituições democráticas frente ao corpo social.

A doutrina majoritariamente tem classificado a confiança depositada nas instituições públicas em duas modalidades, as quais são identificadas com base no alvo da análise feita pelo cidadão. Nas palavras de Bonifácio: "quando o foco das atenções se dá nos comportamentos das pessoas, fala-se em confiança interpessoal. Por sua vez, na confiança institucional, o aspecto levado em consideração é o desempenho da instituição" (2012, p. 399).

É sabido que as instituições democráticas juntamente com seus gestores atuam dentro de balizas previamente estabelecidas, sendo que a sociedade de maneira geral, guarda a apresentação de resultados, igualmente préestabelecidos por parte destes. Desta forma, caso a atuação dos órgãos públicos e seus representantes juntamente com os resultados por estes apresentados se encontrem dentro do esperado, haverá uma inevitável concessão de confiança ao regime por parte da sociedade.

Contudo, caso eventualmente inexista tal prestação por parte das instituições e seus gestores, haverá inevitavelmente uma que do nível de confiança conferido por parte da sociedade, o qual se acentuará na medida em que as próprias instituições não conseguirem apresentar uma resposta rápida e efetiva para o quadro de ineficiência apresentado.

Assim, mostra-se oportuno a manutenção dos mecanismos de participação direita no âmbito das democracias modernas, para que diante desta eventual realidade possa a sociedade rapidamente chamar novamente para si o controle das questões de Estado, conferindo novamente a indispensável legitimidade popular ao regime.

\section{CONSIDERAÇÕES FINAIS.}

Encerrado o presente estudo, pode-se concluir que o regime democrático mostra-se indiscutivelmente como aquele capaz de conferir efetividade aos objetivos do Estado enquanto forma organização política, na medida em que visa permitir uma ativa participação social no âmbito da tomada de decisões.

Diante dessa realidade, a evolução da democracia de certa forma se confunde com a própria linha aprimoramento do Estado Moderno, eis que fora por meio da implementação de mecanismos de ordem democrática que se conseguiu conquistar 
efetivos resultados no âmbito da proteção social e, sobretudo na efetivação dos direitos fundamentais e da dignidade da pessoa humana.

Contudo, o alcance da efetividade democrática não tem se mostrado uma realidade fácil, sendo que com a evolução da sociedade cada vez mais se mostra necessário a constante aprimoração dos mecanismos de representação e participação popular, de forma a ser indispensável a realização de estudos como este, com o fim de se contribuir para o aprimoramento da democracia.

\section{REFERÊNCIAS.}

BIELSCHWSKY, R. Macedo. Das democracias: Democracia Constitucional, 1 ed. São Paulo: Saraiva, 2013, p 51-81.

BOBBIO, N. Estado, Governo, Sociedade: para uma teoria geral da política. Rio de Janeiro: Paz e Terra, 1987.

BONIFÁCIO, R. J. Á. M. (org) - Democracia e confiança: por que os cidadãos desconfiam das instituições públicas?. Revista Brasileira de Ciências Política. [online]. 2012, n.7, p.399-406. Disponível em:

http://dx.doi.org/10.1590/S0103-

33522012000100016. Acesso em: 15 jul. 2018.

DALLARI, D. A. Elementos de Teoria Geral do Estado. São Paulo: Saraiva, 2012.

FACHIN, Z., SAMPAR, R.. Teoria do Estado. São Paulo: Lumen Juris, 2016. p. 125 - 136.

FILOMENO, J. B. Teoria Geral do Estado e da Constituição. 10 ed. Rio de Janeiro: Forense, 2016.

HOBBES, T. Das causas, da geração e da definição de um Estado. Leviatã, 1 ed. São Paulo: Martin Claret, 2014. Cap. XVII p. 142.

MALUF, S. Teoria Geral do Estado. 33 ed. São Paulo: Saraiva, 2017.

PINTO, K. C. Curso de teoria geral do estado: fundamento do direito constitucional positivo. 1 ed. São Paulo: Atlas 2013.

https://doi.org/10.1590/S0103$\underline{33522012000100016}$
Recebido para publicação em 30/03/2018

Revisado em 10/08/2018

Aceito em 16/08/2018 